\title{
Analisis Rasio Keuangan Perbankan Terhadap Profitabilitas
}

\author{
Yogi Yunanto ${ }^{1}$ \\ Fakultas Ekonomi Bisnis \\ Universitas Airlangga, Indonesia \\ Email: Yogi.yunanto-2017@feb.unair.ac.id
}

\author{
Fendy Suhariadi ${ }^{2}$ \\ Fakultas Psikologi \\ Universitas Airlangga, Indonesia
}

\author{
Praptini Yulianti ${ }^{3}$ \\ Fakultas Ekonomi Bisnis \\ Universitas Airlangga, Indonesia
}

\begin{abstract}
ABSTRAK
Penelitian ini dilakukan untuk menguji pengaruh variable bank Size, LDR, NPL, BOPO, NIM, terhadap ROA pada industri perbankan pembangunan daerah di Indonesia. Metode dalam pengumpulan data, penjelasan mengenai definisi opersional variabel, dan penjelasam teknis analisis yang akan dilakukan menggunakan metode kuantitatif. Hasil penelitian ini mendukung Teori Bank Loan Rate Mark Up dimana LDR, NPL dan NIM berpengaruh terhadap ROA, dengan keuntungan bunga yang meningkat mampu meningkatkan ROA.
\end{abstract}

Kata Kunci : $\quad$ Rasio Keuangan; Profitabilitas.

\section{Banking Financial Ratio Analysis To Profitability}

\section{ABSTRACT}

This study was conducted to examine the effect of variable bank size, LDR, NPL, BOPO, NIM, on ROA in the regional development banking industry in Indonesia. The method in data collection, an explanation of the definition of operational variables, and a technical explanation of the analysis will be carried out using quantitative methods. The results of this study support the Bank Loan Rate Mark Up Theory where LDR, $N P L$ and NIM affect ROA, with increasing interest gains can increase ROA.

Keywords : $\quad$ Financial Ratios; Profitability.

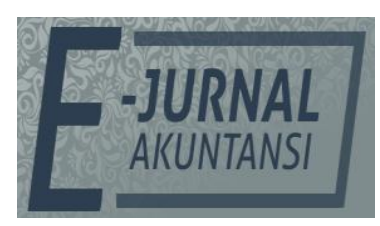

E-JA

e-Jurnal Akuntansi e-ISSN 2302-8556

Vol. 29 No. 2

Denpasar, November

2019

Hal. 716-726

Artikel masuk: 22 September 2019

Tanggal diterima: 18 November 2019 


\section{PENDAHULUAN}

Perbankan merupakan segala sesuatu yang berhubungan dengan bank, yang mencakup tentang kelembagaan, kegiatan usaha serta cara dan proses dalam melaksanakan kegiatan usahanya. Industri perbankan merupakan bagian dari fungsi financial intermediarydiantara pihak-pihak yang telah mempunyai kelebihan dana dengan pihak yang membutuhkan dana. Bank yaitu sebagai agen of trustyang dapat diartikan dimana masyarakat akan menitipkan dananya di bank yang telah dipercayainya. Masyarakat akan percaya apabila uangnya nanti tidak akan disalah gunakan oleh pihak bank, dananya nanti akan dikelola oleh pihak bank dengan sebaik mungkin, pihak bank akan sepenuhnya bertanggung jawab dan tujuannya tidak akan bangkrut dan hasil simpanan dananya akan dapat ditarik kembali.Selain yang dibahas sebelumnya pihak Bank juga berfungsi sebagai agent of development, yaitu dengan kegiatan perekonomian masyarakat di sektor moneter dan di sektor riil tidak akan dapat dipisahkan (Delis, Hasan, \& Tsionas, 2014).

Sebagai badan usaha milik Negara atau milik swasta, kegiatan usaha yang dilaksanakan oleh bank berorientasi agar mendapatkan keuntungan, dengan tujuan untuk memaksimalkan kemakmuran pada pemegang saham atau pada pemilik saham. Pemegang saham atau pemilik akan menanamkan modalnya dengan tujuan agar mendapatkan keuntungan yang telah diperolehnya berupa dividen. Menurut (Salvatore, 2004) tujuan utama dari perusahaan bank adalah untuk memaksimumkan kekayaan atau nilai perusahaan (value of firm) yang telah dicerminkan dari nilai sekarang atas semua keuntungan perusahaan bank yang diharapkan dimasa yang akan datang. Juga untuk keperluanmencapai tujuan tersebut pihak bank dituntut untuk harus mengelola keuangan dengan baik dan benar agar menghasilkan motivasi, inovasi, kinerja yang lebih baik dan sehat.

Profitabilitas bank dalam hal ini diproksi dengan return on asset (ROA). ROA merupakan rasio antara laba bersih setelah pajak terhadap total asset. Semakin besar ROA menunjukkan kinerja yang semakin baik, karena tingkat kembalian semakin besar(Chaniago, 2014). Return on asset adalah hal yang perlu diperhatikan karena dari sisi perusahaan (emiten) ROA dapat digunakan sebagai analisis rasio kemampuan perusahaan dalam mengelola asset yang dimilikinya. Semakin tinggi ROA maka semakin baik pula perusahaan dalam menjalankan kegiatan usahanya. ROA selain untuk emiten, juga bermanfaat bagi pengambilan keputusan para investor maupun kreditur.

Ukuran perusahaan (Size) adalah suatu skala dimana dapat diklasifikasikan besar atau kecil suatu perusahaan. Penentuan ukuran perusahaan ini didasarkan kepada total asset perusahaan(Machfoedz, 1994). Kecenderungan perusahaan yang besar lebih diperhatikan oleh masyarakat, sehingga transaksi yang dihasilkan semakin besar pula, yang akhirnya akan berdampak pada profitabilitas yang dihasilkan. Variabel ukuran bank (bank size) mempunyai suatu pengaruh yang positif pada Return On Assets (ROA) bank. Hasil penelitian tersebut didukung oleh(Chen, Wei, Zhang, \& Shi, 2013) yang juga menunjukkan bahwa ukuran (size) berpengaruh negatif signifikan terhadap profitabilitas bank. Semakin besar perusahaan (perbankan) maka cakupan usaha atau pangsa pasar yang dikuasainya lebih besar, sehingga dapat meningkatkan 
efisiensi. Meningkatnya efisiensi usaha mempunyai dampak positif terhadap profitabilitas dari perbankan tersebut(Enqvist, Graham, \& Nikkinen, 2014).

LDR yaitu rasio yang telah mengukur kemampuan pada bank untuk dapat memenuhi kewajiban keuangan yang wajib dipenuhi. Kewajiban tersebut yaitu berupa call money yang wajib dipenuhi disaat adanya kewajiban pada kliring, dengan pemenuhannya dilaksanakan mulai dari aktiva lancar yang telah dimiliki oleh perusahaan. Penelitian pada LDR yang telah diteliti oleh(Vodová, 2014) menunjukkan gagasannya bahwa pada LDR berpengaruh signifikan positif terhadap ROA pada bank di Negara Hungaria. Menurut (Gelos, 2009)berpendapat bahwa LDR mempunyai pengaruh yang negatif dan signifikan terhadap ROA. Dengan adanya Research gap dari penelitian ini maka perlu dilakukan penelitian lanjutan tentang pengaruh LDR terhadap ROA.

NPL mencerminkan risiko kredit, semakin kecil NPL maka semakin kecil pula risiko kredit yang ditanggung pihak bank. Agar nilai bank terhadap rasio ini baik Bank Indonesia menetapkan kriteria rasio NPL dibawah 5\%. Semakin tinggi NPL maka ROA akan semakin kecil yang diakibatkan oleh pendapatan kredit macet. Hasil study (Mayes \& Stremmel, 2012)menunjukkan bahwa NPL berpengaruh signifikan positif terhadap ROA. Hasil penelitian(Mayes \& Stremmel, 2012) bertentangan dengan penelitian yang dilakukan oleh(Brigitte Liebig, Karin Gottschall, 2016) yang menunjukkan adanya pengaruh yang signifikan negatif dari NPL terhadap ROA. Dengan adanya research gap dari penelitian(Mayes \& Stremmel, 2012)dan Schweiger dan(Brigitte Liebig, Karin Gottschall, 2016)maka perlu dilakukan penelitian lanjutan tentang pengaruh NPL dan ROA.

Biaya Operasioanal Terhadap Pendapatan Operasi mencerminkan tingkat efisiensi bank dalam menjalankan operasionalnya. BOPO merupakan perbandingan dari biaya yang dikeluarkan oleh bank dalam menjalankan aktivitas utamanya terhadap pendapatan yang diperoleh dari aktivitas tersebut. Aktivitas utama bank seperti biaya bunga, biaya tenaga kerja, biaya pemasaran dan biaya operasional lainnya. Sedangkan pendapatan operasional adalah pendapatan bunga yang diperoleh dari penempatan dana dalam bentuk kredit dan pendapatan operasi lainnya. BOPO menunjukkan efisiensi bank dalam menjalankan usaha pokoknya terutama kredit berdasarkan jumlah dana yang berhasil dikumpulkan. Dalam pengumpulan dana terutama dana masyarakat (dana pihak ketiga), diperlukan biaya selain biaya bunga (termasuk biaya iklan). BOPO yang diteliti oleh (Gounder \& Sharma, 2012) menunjukkan bahwa BOPO berpengaruh signifikan positif terhadap ROA. Sementara(Brigitte Liebig, Karin Gottschall, 2016) menunjukkan bahwa BOPO mempunyai pengaruh signifikan negatif terhadap ROA.

NIM menunjukkan kemampuan bank dalam menghasilkan pendapatan dari bunga dengan melihat kinerja bank dalam menyalurkan kredit, mengingat pendapatan operasional bank sangat tergantung dari selisih bunga (spread) dari kredit yang disalurkan. Pendapatan diperoleh dari bunga yang diterima dari pinjaman yang diberikan dikurangi dengan biaya bunga dari sumber dana yang dikumpulkan. NIM suatu bank sehat bila memiliki NIM diatas 2\%. NIM yang diteliti oleh (Berrospide \& Edge, 2010), menunjukkan bahwa NIM berpengaruh signifikan negatif terhadap ROA. Sementara hasil riset (Dumicic \& Rizdak, 2013) 
menunjukan pengaruh yang signifikan positif antara NIM dan ROA. Berdasarkan hasil dari kedua penelitian tersebut, peneliti melihat adanya research gap sehingga perlu dilakukan penelitian lanjutan.

Nilai rata-rata LDR, NPL, BOPO, NIM dan ROA Bank Pembangunan Daerah di Indonesia pada tahun 2009-2014 dapat dilihat dari Tabel 1 berikut ini:

Tabel 1. Rata-rata LDR, NPL, BOPO,NIM dan ROA Bank Pembangunan Daerah Tahun

\begin{tabular}{cccccc}
\hline Tahun & LDR $(\%)$ & NPL $(\%)$ & BOPO $(\%)$ & NIM $(\%)$ & ROA (\%) \\
\hline 2009 & 65,06 & 3,55 & 80,21 & 7,16 & 3,36 \\
2010 & 67,59 & 3,49 & 80,09 & 7,88 & 3,11 \\
2011 & 69,26 & 3,96 & 83,75 & 8,52 & 3,98 \\
2012 & 79,67 & 3,59 & 79,75 & 8,99 & 4,26 \\
2013 & 80,1 & 4,02 & 82,29 & 9,01 & 3,84 \\
2014 & 80,67 & 3,89 & 88,75 & 8,51 & 4,08 \\
\hline
\end{tabular}

Sumber: Asosiasi Bank Pembangunan Daerah yang diolah kembali, 2014

Berdasarkan data pada tahun 2009 sampai dengan tahun 2010 menunjukkan bahwa nilai rata-rata Profitabilitas yang di proksikan dengan ROA pada Bank Pembangunan Daerah di Indonesia mengalamipenurunan dari 3,36\% menjadi 3,11\%.Kemudian pada tahun 2011 sampai tahun 2012 mengalami kenaikan dari 3,98\% menjadi 4,26\% . Namun pada tahun 2012 dan 2013, nilai ROA tersebut mengalami penurunan menjadi 4,26\% dan 3,84\%. Pada tahun 2013 menuju tahun 2014 nilai ROA kembali naik dari 3,84\% menjadi 4,08\%.

Mempermudah kajian literatur penelitian sebelumnya, disajikan ringkasan dari penelitian-penelitian tersebut diatas dalam Tabel 2 sebagai berikut:

Tabel 2. Research Gap

\begin{tabular}{|c|c|c|c|c|}
\hline No & Permasalahan & Research Gap & Penulis & $\begin{array}{l}\text { MetodePeneli } \\
\text { tian }\end{array}$ \\
\hline 1. & $\begin{array}{l}\text { Hubungan antara } \\
\text { LDR dengan ROA }\end{array}$ & $\begin{array}{ll}\text { a. } & \text { Sinifikan } \\
& \text { positif } \\
\text { b. } & \text { Signifikan } \\
\text { negatif }\end{array}$ & $\begin{array}{ll}- & \text { Shimizu (2010) } \\
- & \text { Vodova (2012) } \\
- & \text { Gelos }(2006)\end{array}$ & $\begin{array}{ll}- & \text { Analisis } \\
& \text { Regresi } \\
-\quad & \text { Analisis } \\
& \text { regresi }\end{array}$ \\
\hline 2 & $\begin{array}{l}\text { Hubungan antara } \\
\text { NPL dengan ROA }\end{array}$ & $\begin{array}{ll}\text { a. } & \text { Signifikan } \\
\text { positif } \\
\text { b. } \\
\begin{array}{l}\text { Signifikan } \\
\text { negatif }\end{array}\end{array}$ & $\begin{array}{ll}\text { - } & \text { Mayes dan } \\
& \text { Stremmel (2012) } \\
\text { - } & \text { Schweiger dan } \\
& \text { Liebeg, (2014) }\end{array}$ & $\begin{array}{ll}\text { - } & \text { Analisis } \\
& \text { regresi } \\
\text { - } & \text { Analisis } \\
& \text { regresi }\end{array}$ \\
\hline 3 & $\begin{array}{l}\text { Hubungan antara } \\
\text { BOPO dengan ROA }\end{array}$ & $\begin{array}{ll}\text { a. } & \text { Signifikan } \\
\text { positif } \\
\text { b. } & \text { Signifikan } \\
\text { negatif }\end{array}$ & $\begin{array}{ll}\text { - } & \text { Gounder dan } \\
& \text { Sharma, (2012) } \\
\text { - } & \text { Schweiger dan } \\
& \text { Liebeg, (2014) }\end{array}$ & $\begin{array}{ll}\text { - } & \text { Analisis } \\
& \text { regres } \\
\text { - } & \text { Analisis } \\
& \text { regresi }\end{array}$ \\
\hline 4 & $\begin{array}{l}\text { Hubungan antara } \\
\text { NIM dengan ROA }\end{array}$ & $\begin{array}{ll}\text { a. } & \text { Signifikan } \\
\text { positif } \\
\text { b. } \\
\begin{array}{l}\text { Signifikan } \\
\text { negatif }\end{array}\end{array}$ & $\begin{array}{ll}\text { - } & \text { Dumicic (2013) } \\
\text { - } & \text { Berrospide dan } \\
& \text { Edge, }(2010),\end{array}$ & $\begin{array}{ll}\text { - } & \text { Analisis } \\
& \text { regresi } \\
\text { - } & \text { Analisis } \\
& \text { regresi }\end{array}$ \\
\hline 5 & $\begin{array}{l}\text { Hubungan antara } \\
\text { Bank Size dengan } \\
\text { ROA }\end{array}$ & $\begin{array}{ll}\text { a. } & \text { Signifikan } \\
\text { positif } \\
\text { b. } & \text { Signifikan } \\
\text { negatif }\end{array}$ & $\begin{array}{l}\text { Tatum (2012) } \\
\text { Limpaphayom } \\
\text { dan Polwitoon } \\
(2004)\end{array}$ & $\begin{array}{ll}\text { - } & \text { Analisis } \\
\text { regresi } \\
\text { - } \quad \text { Analisis } \\
\text { regresi }\end{array}$ \\
\hline
\end{tabular}

Sumber : Data Penelitian, 2018 
Permasalahan dalam penelitian ini karena adanya perbedaan dalam research gap dari penelitian terdahulu sehingga perlu dilakukan penelitian lanjutan yang meneliti permasalahan faktor-faktor yang mempengaruhi Return On Asset (ROA). Faktor - faktor tersebut antara lain Ukuran Bank (Bank Size), LDR (Loan toDeposit Ratio), NPL (Non Perfoming Loan), BOPO (Biaya Operasioanal Terhadap Pendapatan Operasi) dan NIM (Net Interest Margin). Riset problem dalam penelitian ini adalah masih terdapat Inkonsistensi hasil penelitian mengenai variable yang berpengaruh terhadap Profitabilitas (ROA) Bank dan ROA selama 6 tahun cenderung naik atau turun.

\section{METODE PENELITIAN}

Metode penelitian iniakan dilaksanakan oleh penulis terdiri dari pembahasan mengenai jenis dan sumber data yang diambil dalam penelitian ini dan populasi yang menjadi obyek penelitian, metode dalam pengumpulan data, penjelasan mengenai definisi opersional variabel, dan penjelasam teknis analisis yang akan dilakukan.

Obyek Penelitian iniakan dilaksanakan di Bank Pembangunan Daerah Indonesia berjumlah 26 Bank Pembangunan Daerah yang ada di seluruh Indonesia.

Dalam penelitian ini data yang digunakan adalah data sekunder, yaitu data yang diperoleh langsung dari Laporan Keuanedegan Tahunan Bank Pembangunan daerah Seindonesia Tahun 2011 sampai dengan 2014. Data diperoleh dari Website Asosiasi Perbankan Daerah(Otoritas Jasa Keuangan, 2013)

Definisi operasional dalam penelitian ini menggunakan variabel sebagai berikut: Variabel dependen (variabel Y) yaitu variabel yang nilainya dipengaruhi oleh variabel independen. Variabel dependen dalam penelitian ini adalah aspek profitabilitas yang diukur dengan ROA. Dan Variabel independen (variabel X) yaitu variabel yang menjadi sebab terjadinya atau terpengaruhinya variabel dependen. Variabel independen dalam penelitian ini adalah: Bank Size, LDR, NPL, BOPO, dan NIM

Dalam penelitian ini, variabel dependen yang digunakan adalah ROA. ROA digunakan untuk mengukur kemampuan manajemen bank dalam memperoleh keuntungan atau laba secara keseluruhan.Semakin besar ROA suatu bank, semakin besar pula tingkat keuntungan yang dicapai oleh bank tersebut dan semakin baik pula posisi bank tersebut dari segi penggunaan asset(Sukarno \& Syaichu, 2006).

ROA $=\frac{\text { Laba Sebelum Pajak }}{\text { Total Aktiva }} \times 100 \%$

Ukuran Bank atau Bank size diproksi dengan total asset dalam bentuk logaritma natural. Variabel ini dapat menunjukkan skala usa yang dilakukan oleh sebuah perusahaan, sehingga untuk mengurangi gap antar data tersebut variabel ukuran (size) di Ln. Hal ini untuk menormalkan besaran nilainya data ini.

Size $=$ Ln Total Aktiva

Loan to deposit ratio adalahrasio yang menunjukkan tingkat likuiditas suatu bank. LDR juga menunjukkan kemampuan dalam menjalankan fungsi intermediasinya (kewajibannya) dalam menyalurkan dana pihak ketiga ke 
kredit.Kewajiban tersebut berupa call money yang harus dipenuhi pada saat adanya kewajiban kliring, dimana pemenuhannya dilakukan dari aktiva lancer yang dimiliki perusahaan(Setyarini, 2010). Rasio ini dapat dirumuskan sebagai berikut :

$L D R=$

$\frac{\text { Total Kredit }}{\text { Total Dana Pihak Ketiga }} \times 100 \%$

Rasio NPL adalah adalah perbandingan antara kredit bermasalah terhadap total kredit.Rasio ini menunjukan kemampuan manajemen bank dalam mengelola kredit bermasalah. Kredit bermasalah didefinisikan sebagai resiko yang dikaitkan dengan kemungkinan kegagalan klien membayar kewajibannya atau resiko dimana debitur tidak dapat melunasi hutangnya(Hermina \& Suprianto, 2014). NPL mencerminkan resiko kredit, semakin kecil NPL maka ssemakin kecil pula resiko kredit yang ditanggung pihak bank. Rasio ini dapat dirumuskan sebagai berikut:

$N P L=\frac{\text { Jumlah Kredit Bermasalah }}{\text { Total Kredit }} \times 100 \%$

Menurut Peraturan Bank Indonesia Nomor 14/26/PBI/2012 tentang Kegiatan Usaha dan Jaringan Kantor Berdasarkan Modal Inti Bank, Bank Indonesia menetapkan bahwa Pencapaian tingkat efisiensi Bank antara lain diukur melalui rasio Biaya Operasional terhadap Pendapatan Operasional (BOPO). Rasio ini dapat dirumuskan sebagai berikut :

$B O P O=$

$\frac{\text { Biaya Operasional }}{\text { Pendapatan Operasional }} \times 100 \%$.

Net Interest Margin (NIM) merupakan rasio untuk penilaian profitabilitas bank. Net Interest Margin (NIM)merupakan pembagian antara pendapatan bunga bersih yaitu pendapatan bunga yang diperoleh bank dikurangi biaya bunga yang harus dikeluarkan dibagi dengan rata-rata aktiva produktif. Aktiva produksi yang diperhitungkan adalah aktiva produktif yang menghasilkan bunga. Net Interest Margin (NIM) menurut (Setyarini, 2010):

$N I M=\frac{\text { Pendapatan Bunga Bersih }}{\text { Rata-Rata aktiva produktif }} \times 100 \%$.

Berdasarkan uraian sebelumnya, variabel dependen dan independen dapat diringkas dalam tabel berikut:

\section{HASIL DAN PEMBAHASAN}

Nilai koefisien determinasi menunjukkan persentase variabel dependen yang dapat dijelaskan oleh variabel-variabel independen. Nilai koefisien determinasi dapat diperoleh dari nilai adjusted $\mathrm{R}^{2}$. Berdasarkan hasil output SPSS besarnya nilai adjusted $R^{2}$ dapat dilihat pada Tabel 4 . Sebagai berikut:

Tabel 4. Koefisien Determinasi

\begin{tabular}{lccr}
\hline Model & $\mathrm{R} \quad$ R Square & $\begin{array}{c}\text { Model Summary } \\
\text { Adjusted } \\
\text { Square }\end{array}$ & Std. Error of the Estimate \\
\hline 1 .653a & .562 & .505 & 11.98474 \\
$\begin{array}{l}\text { a. Predictors: (Constant), NIM, BOPO, BS, NPL, LDR } \\
\text { b. Dependent Variable: ROA }\end{array}$ & & \\
Sumber: Data Penelitian, 2018 &
\end{tabular}


Berdasarkan hasil output SPSS nampak bahwa pengaruh secara bersamasama lima variabel independen tersebut (bank size, LDR, NPL, BOPO, dan NIM) terhadap ROA. Berdasarkan hasil output SPSS nampak bahwa pengaruh secara parsial lima variabel independen tersebut (bank size, LDR, NPL, BOPO, dan NIM) terhadap ROA seperti ditunjukkan pada Tabel 5. Sebagai berikut:

Tabel 5. Perhitungan Regresi Parsial

\begin{tabular}{|c|c|c|c|c|c|c|}
\hline \multicolumn{7}{|c|}{ Coefficientsa } \\
\hline & \multirow[t]{2}{*}{ Model } & \multicolumn{2}{|c|}{$\begin{array}{c}\text { Unstandardized } \\
\text { Coefficients }\end{array}$} & \multirow{2}{*}{$\begin{array}{c}\begin{array}{c}\text { Standardized } \\
\text { Coefficients }\end{array} \\
\text { Beta }\end{array}$} & \multirow[t]{2}{*}{$t$} & \multirow[t]{2}{*}{ Sig. } \\
\hline & & B & Std. Error & & & \\
\hline \multirow[t]{6}{*}{1} & (Constant) & 21.130 & 30.423 & & .695 & .489 \\
\hline & Bank size & .074 & 401 & .017 & 185 & .854 \\
\hline & LDR & 237 & .072 & .317 & 3.320 & .001 \\
\hline & NPL & -2.348 & .719 & -.291 & -3.264 & .002 \\
\hline & ВОРО & -.431 & .349 & -.110 & -1.236 & .220 \\
\hline & NIM & .976 & 471 & 208 & 2.072 & .049 \\
\hline
\end{tabular}

Sumber: Data Penelitian, 2018

Dari Tabel 5 maka dapat disusun persamaan regresi linier berganda sebagai berikut:

ROA $=21,130+0,074 \mathrm{BS}+0,237 \mathrm{LDR}-2,348 \mathrm{NPL}-0,431 \mathrm{BOPO}+0,976 \mathrm{NIM}$

\section{Tabel 6. Ringkasan Hipotesis}

\begin{tabular}{|c|c|c|c|}
\hline Hipotesis & Perumusan & $\begin{array}{c}\text { Nilai } \\
\text { Signifikan }\end{array}$ & Kesimpulan \\
\hline 1 & $\begin{array}{l}\text { Bank Size berpengaruh positif terhadap } \\
\text { Profitabilitas }\end{array}$ & 0.854 & $\begin{array}{c}\text { Ditolak } \\
\text { (Nilai Sig > } \\
0,05)\end{array}$ \\
\hline 2 & $\begin{array}{l}\text { LDR berpengaruh positif terhadap } \\
\text { Profitabilitas }\end{array}$ & 0.001 & $\begin{array}{c}\text { Diterima } \\
\text { (Nilai Sig < } \\
0,05)\end{array}$ \\
\hline 3 & $\begin{array}{l}\text { Non Performing Loan(NPL) berpengaruh } \\
\text { Negatif terhadap Profitabilitas }\end{array}$ & 0.002 & $\begin{array}{c}\text { Diterima } \\
(\text { Nilai Sig }< \\
0,05)\end{array}$ \\
\hline 4 & $\begin{array}{l}\text { BOPO berpengaruh Negatif terhadap } \\
\text { profitabilitas }\end{array}$ & 0.220 & $\begin{array}{c}\text { Ditolak } \\
\text { (Nilai Sig > } \\
0,05)\end{array}$ \\
\hline 5 & $\begin{array}{l}\text { Net Interest Margin (NIM) berpengaruh } \\
\text { positif terhadap Profitabilitas }\end{array}$ & 0.049 & $\begin{array}{c}\text { Diterima } \\
\text { (Nilai Sig }< \\
0,05)\end{array}$ \\
\hline
\end{tabular}

Sumber: Data Penelitian, 2018

Berdasarkan data mentah yang diinput dari laporan keuangan Bank Pembangunan Daerah se-Indonesia periode Tahun 2011-2014 maka dapat dihitung rasio-rasio keuangan yang digunakan dalam penelitian ini yang meliputi bank size, LDR, NPL, BOPO, NIM, dan ROA. Selanjutnya nilai minimum, maksimum, rata-rata (mean) dan standar deviasi dari masing-masing variabel penelitian dapat dilihat pada Tabel 7. 
Tabel 7. Perhitungan Nilai Minimum, Maksimun, Mean, Standar Deviasi

\begin{tabular}{|c|c|c|c|c|c|}
\hline \multicolumn{6}{|c|}{ Descriptive Statistics } \\
\hline & $\mathrm{N}$ & Minimum & Maximum & Mean & $\begin{array}{l}\text { Std. } \\
\text { Deviation }\end{array}$ \\
\hline $\begin{array}{l}\text { Bank } \quad \text { Size } \\
\text { (Ln) }\end{array}$ & 104 & 13.53 & 18.09 & 15.9923 & 3.08372 \\
\hline LDR (\%) & 104 & 18.52 & 128.43 & 83.5093 & 17.93736 \\
\hline NPL (\%) & 104 & .05 & 9.01 & 1.8799 & 1.66917 \\
\hline BOPO (\%) & 104 & 64.89 & 99.38 & 79.3240 & 3.43508 \\
\hline NIM (\%) & 104 & 2.33 & 15.10 & 7.9274 & 1.91563 \\
\hline ROA (\%) & 104 & .01 & 60.00 & 18.6872 & 13.44745 \\
\hline $\begin{array}{ll}\text { Valid } & \mathrm{N} \\
\text { (listwise) } & \end{array}$ & 104 & & & & \\
\hline
\end{tabular}

Sumber: Data Penelitian, 2018

Tabel 7 menjelaskan statistik deskriptif dari masing-masing variabel, dimana $\mathrm{N}$ merupakan jumlah data amatan, minimum merupakan nilai terendah atas variabel yang dihasilkan perusahaan sampel, maximum merupakan nilai tertinggi atas variabel yang dihasilkan perusahaan sampel, mean merupakan nilai rata-rata atas variabel yang dihasilkan perusahaan sampel, dan standard deviation merupakan nilai penyimpangan data. Rasio profitabilitas yang di ukur dengan return on asset (ROA) menunjukkan seberapa besar laba yang akan diperoleh untuk setiap total aktivanya, sehingga semakin besar return on asset (ROA) menunjukkan kemampuan perusahaan mendapatkan laba semakin tinggi. Berdasarkan hasil perhitungan pada Tabel 4.1 bahwa nilai minimum ROA sebesar $0,01 \%$, nilai maximum ROA sebesar $60 \%$ dan rata-rata return on Asset (ROA) sebesar 18,6872\% dengan standar deviasi (SD) sebesar 13,44745\%. Hasil tersebut menunjukan bahwa nilai standar deviasi (SD) lebih kecil daripada ratarata ROA yang menunjukan bahwa data variable ROA mengindikasikan hasil yang baik. Hal tersebut dikarenakan nilai standar deviasi yang mencerminkan penyimpangan dari data variabel tersebut relative rendah karena lebih kecil dari nilai rata-ratanya.bank size, LDR, NPL, BOPO, dan NIM menunjukkan trend yang sama dengan ROA.

Ukuran Bank atau Bank size diproksi dengan total asset dalam bentuk logaritma natural. Variabel ini dapat menunjukkan besarnya asset yang dimiliki olehperusahaan, sehingga untuk mengurangi gap antar data tersebut variabel ukuran (size) di Ln.Nilai minimum bank size sebesar Ln 13,53 atau Rp. 754.178.000.000,- diperoleh perusahaan Bank BPD Sulawesi Tengah Tahun 2012, dan nilai maksimum bank size sebesar Ln 18,08 atau Rp. 71.467.965.000.000,diperoleh perusahaan Bank BPD BJB pada Tahun 2014.

Loan to deposit ratio adalahrasio yang menunjukkan tingkat likuiditas suatu bank. LDR juga menunjukkan kemampuan dalam menjalankan fungsi intermediasinya (kewajibannya) dalam menyalurkan dana pihak ketiga ke kredit.Kewajiban tersebut berupa call money yang harus dipenuhi pada saat adanya kewajiban kliring, dimana pemenuhannya dilakukan dari aktiva lancar yang dimiliki perusahaan. Nilai terendah LDR sebesar 18,52\% diperoleh perusahaan Bank BPD Jatim Tahun 2013, dan nilai maksimum sebesar 128,43\% diperoleh perusahaan Bank BPD Sulteng pada Tahun 2013. 
Rasio NPL adalah adalah perbandingan antara kredit bermasalah terhadap total kredit.Rasio ini menunjukan kemampuan manajemen bank dalam mengelola kredit bermasalah. Kredit bermasalah didefinisikan sebagai resiko yang dikaitkan dengan kemungkinan kegagalan klien membayar kewajibannya atau resiko dimana debitur tidak dapat melunasi hutangnya . Nilai terendah NPL sebesar 0,05\% diperoleh perusahaan Bank BPD Papua Tahun 2014, dan nilai maksimum sebesar 9,01\% diperoleh perusahaan Bank BPD Sumsel dan Babel pada Tahun 2013.

BOPO adalah rasio antara Biaya Operasi Terhadap Pendapatan Operasi. Nilai terendah BOPO sebesar 64,89\% diperoleh perusahaan Bank BPD Bali Tahun 2014, dan nilai maksimum sebesar 99,38\% diperoleh perusahaan Bank BPD Maluku pada Tahun 2014.

Net Interest Margin (NIM) merupakan rasio untuk penilaian profitabilitas bank. Net Interest Margin (NIM)merupakan pembagian antara pendapatan bunga bersih yaitu pendapatan bunga yang diperoleh bank dikurangi biaya bunga yang harus dikeluarkan dibagi dengan rata-rata aktiva produktif. Nilai terendah NIM sebesar 2,33\% diperoleh perusahaan Bank BPD Sulawesi Tenggara Tahun 2014, dan nilai maksimum sebesar 15,10\% diperoleh perusahaan Bank BPD Sulawesi Tenggara pada Tahun 2011.

ROA digunakan untuk mengukur kemampuan manajemen bank dalam memperoleh keuntungan atau laba secara keseluruhan. Semakin besar ROA suatu bank, semakin besar pula tingkat keuntungan yang dicapai oleh bank tersebut dan semakin baik pula posisi bank tersebut dari segi penggunaan asset (Sukarno dan Syaichu, 2006). Nilai terendah ROA sebesar 0,01\% diperoleh perusahaan Bank BPD Maluku Tahun 2014, dan nilai maksimum sebesar $60 \%$ diperoleh perusahaan Bank BPD Sulteng pada Tahun 2013.

Hasil penelitian ini menunjukkan bahwa rasio-rasio keuangan bank (terutama LDR, NPL dan NIM) mampu memprediksi ROA pada Bank Pemerintah Daerah di Indonesia Periode tahun 2011-2014. Sisi positif dari hasil penelitian ini adalah mempertegas hasil penelitian sebelumnya yang menyebutkan bahwa variable LDR, NPL dan NIM ke dalam model regresi untuk memprediksi nilai ROA, dimana hasil penelitian ini adalah menegaskan bahwa variable LDR, NPL dan NIM mempunyai pengaruh yang signifikan terhadap ROA. Hasil penelitian ini mendukung Teori Bank Loan Rate Mark Up dimana LDR, NPL dan NIM berpengaruh terhadap ROA, dengan keuntungan bunga yang meningkat mampu meningkatkan ROA.

\section{SIMPULAN}

LDR berpengaruh positif terhadap ROA, dalam penelitian ini rata-rata nilai LDR sebesar 83,5093\%. Manajemen bank perlu memperhatikan LDR, karena LDR merupakan kemampuan bank untuk menyalurkan kredit agar bank dapat meningkatkan ROA sehingga LDR harus ditingkatkan yang disertai dengan pengelolaan kredit yang lebih baik. Oleh karena itu agar dapat meningkatkan ROA, perusahaan dapat meningkatkan LDR nya dengan terkendali antara 7892\% agar selama peningkatan LDR masih dapat meningkatkan ROA. NPL berpengaruh negative terhadap ROA, dalam penelitian ini rata-rata nilai NPL 
sebesar 1,8799\%. Manajemen bank perlu menurunkan NPL yang berpengaruh negative terhadap ROA. Agar dapat meningkatkan ROA, perusahaan dapat menurunkan NPL nya dengan terkendali dibawah 5\% agar selama penurunan NPL masih dapat meningkatkan ROA. NIM berpengaruh positif terhadap ROA, dalam penelitian ini rata-rata nilai NIM sebesar 7,9274. ROA dapat ditingkatkan dengan meningkatkan NIM dengan cara mengelola assetnya dengan baik dengan terus menjaga besarnya NIM dan melakukan efisiensi dalam menghasilkan pendapatan bunga bank yang optimal. Perusahaan dapat meningkatkan NIM dengan terkendali diatas $2 \%$ agar selama peningkatan NIM masih dapat meningkatkan ROA.

\section{REFRENSI}

Berrospide, J. M., \& Edge, R. M. (2010). The effects of bank capital on lending: What do we know, and what does it mean? International Journal of Central Banking, 6(4), 5-54.

Brigitte Liebig, Karin Gottschall, B. S. (2016). Gender Equality in Context: Policies and Practices in Switzerland.

Chaniago, N. (2014). Analisa Struktur Pasaran dan Efisiensi Industri Perbankan di Indonesia Periode 2007-2012.

Chen, Y., Wei, X., Zhang, L., \& Shi, Y. (2013). Sectoral diversification and the banks' return and risk: Evidence from Chinese listed commercial banks. Procedia Computer Science, 18, 1737-1746. https://doi.org/10.1016/j.procs.2013.05.342

Delis, M. D., Hasan, I., \& Tsionas, E. G. (2014). The risk of financial intermediaries. Journal of Banking and Finance, 44(1), 1-12. https:// doi.org/10.1016/j.jbankfin.2014.03.024

Dumicic, M., \& Rizdak, T. (2013). Determinants of banks' net interest margins in Central and Eastern Europe. Financial Theory and Practice, 37(1), 1-30. https://doi.org/10.3326/fintp.37.1.1

Enqvist, J., Graham, M., \& Nikkinen, J. (2014). The impact of working capital management on firm profitability in different business cycles: Evidence from Finland. Research in International Business and Finance, 32, 36-49. https://doi.org/10.1016/j.ribaf.2014.03.005

Gelos, R. G. (2009). Banking spreads in Latin America. Economic Inquiry, 47(4), 796-814. https://doi.org/10.1111/j.1465-7295.2008.00144.x

Gounder, N., \& Sharma, P. (2012). Determinants of bank net interest margins in Fiji, a small island developing state. Applied Financial Economics, 22(19), 1647-1654. https://doi.org/10.1080/09603107.2012.674202

Hermina, R., \& Suprianto, E. (2014). Analisis Pengaruh CAR, NPL, LDR dan BOPO Terhadap Profitabilitas (ROE) pada Bank Umum Syariah. Jurnal Akuntansi Indonesia, 3(2), 129-142. Retrieved from http://jurnal.unissula.ac.id/index.php/jai/article/view/901

Machfoedz, M. (1994). Financial Ratio Analysis and the Prediction of Earning Changes in Indonesia. Kelola.

Mayes, D. G., \& Stremmel, H. (2012). The Effectiveness of Capital Adequacy Measures in Predicting Bank Distress. SSRN Electronic Journal, (December), 1-46. https://doi.org/10.2139/ssrn.2191861 
Otoritas Jasa Keuangan. (2013). Statistik Perbankan Indonesia, Indonesian Banking Statistics. Statistik Perbankan Indonesia, 11(12), 1-136.

Salvatore, D. (2004). Growth and poverty in a globalizing world. Journal of Policy Modeling, 26(4), 543-551. https://doi.org/10.1016/j.jpolmod.2004.04.009

Setyarini, A. (2010). Analisis Pengaruh CAR, NIM, BOPO, LDR, GMW Terhadap Perubahan LABA (Studi Pada Bank Pembangunan Daerah Di Indonesia Periode 2005-2007). Jurnal Bisnis Strategi, 19(1), 1-9.

Sukarno, K. W., \& Syaichu, M. (2006). Analisis Faktor-Faktor Yang Mempengaruhi Kinerja Bank Umum Di Indonesia. Jurnal Studi Manajemen $\mathcal{E}$ Organisasi, 3(2), 46-58. https://doi.org/10.14710/jsmo.v3i2.4193

Vodová, P. (2014). Determinants of Commercigunal Banks' Liquidity in the Czech Republic 12 Bank Liquidity and its Measuring 3 Determinants of Bank Liquidity, (January 2011), 92-97. 